\title{
Non-Destructive Evaluation of Internal Sulphate Attack in Cement-Based Materials Applying Non- Linear Ultrasonic Techniques ${ }^{\dagger}$
}

\author{
José Marcos Ortega 1,*, Marina Miró ${ }^{1}$, Pedro Poveda ${ }^{2}$, Antonio José Tenza-Abril ${ }^{1}$, Jaime Ramis ${ }^{2}$ \\ and Miguel Ángel Climent ${ }^{1}$ \\ 1 Departamento de Ingeniería Civil, Universidad de Alicante, Ap. Correos 99, 03080 Alacant/Alicante, Spain; \\ m.miro@ua.es (M.M.); ajt.abril@ua.es (A.J.T.-A.); ma.climent@ua.es (M.Á.C.) \\ 2 DFISTS, Universidad de Alicante, Ap. Correos 99, 03080 Alacant/Alicante, Spain; \\ pedro.poveda@ua.es (P.P.); jramis@ua.es (J.R.) \\ * Correspondence: jm.ortega@ua.es; Tel.: +34-96-5903-400 \\ + Presented at 1st International Electronic Conference on Applied Sciences, 10-30 November 2020; Available \\ online: https://asec2020.sciforum.net/.
}

Published: 10 November 2020

\begin{abstract}
One of the most aggressive attacks to which cement-based materials can be exposed is that produced by sulphate. During this attack expansive products are formed, causing volumetric strains in hardened materials, which brings microcracking and the reduction of their strength and durability. The use of non-destructive techniques for characterizing the microstructure of cementbased materials, and for following the development of deleterious processes which can affect them, has become an important research field. Among them, non-linear ultrasonic (NLU) techniques have shown to be useful for evaluating the material degradation. The aim of this work is to study the possibility of using the NLU technique for the non-destructive evaluation of initial development of internal sulphate attack in cement-based materials. Cement pastes were prepared using ordinary Portland cement, to which an appropriate amount of calcium sulphate 2-hydrate was added during the setting for producing an internal attack in the samples. Furthermore, its effects in the microstructure have been followed with mercury intrusion porosimetry. The expansion and linear ultrasonic pulse velocity were also determined. The preliminary results indicate that the NLU technique could be useful for studying the development of sulphate attack in the short-term, complementing the information provided by other techniques.
\end{abstract}

Keywords: sulphate attack; non-destructive characterization; microstructure; ultrasonic wave; cement-based materials

\section{Introduction}

One of the most harmful aggressive attack to which cement-based materials can be exposed is that produced by sulphate. The sulphate attack consists of a complex mechanism, which involves different chemical reactions between components of cement paste microstructure and sulphate ions [1]. Along this attack, expansive products are formed, causing volumetric strains in the hardened material, which brings microcracking and a loss of pore refinement [2]. In addition to this, as consequence of those damages in the microstructure, it is also produced a loss of strength and durability in the cement-based materials exposed to sulphate attack [3].

Nowadays, the use of non-destructive techniques for characterizing of the microstructure and service properties of cement-based materials has become an important research field. In particular, these non-destructive techniques can also be useful for following the development of deleterious processes produced during the attack of aggressive substances to these cement-based materials. 
Among them, non-linear ultrasonic (NLU) techniques have been shown to be useful for the evaluation of material degradation, and there are recent studies in which it has been used for detecting cracks due to steel corrosion in reinforced concrete structures [4,5].

In view of that, the objective of this work is to study the possibility of using the NLU technique for the non-destructive evaluation of the initial stages of internal sulphate attack in cement-based materials.

\section{Materials and Methods}

\subsection{Materials and Sample Preparation}

The tests were performed on cement pastes, which were prepared using ordinary Portland cement CEM I 42.5 R (Spanish and European standard UNE-EN 197-1). First of all, specimens subject to internal sulphate attack were prepared according to the ASTM Standard C452-02. The test method described in this standard consisted of making the specimens from a mixture of cement and gypsum in such proportions that the mixture has a sulfur trioxide $\left(\mathrm{SO}_{3}\right)$ context of $7 \%$ in mass [6]. Therefore, for achieving that content of $\mathrm{SO}_{3}$, the samples subject to internal sulphate attack were made with a binder consisting of $90.8 \%$ of CEM I $42.5 \mathrm{R}$ and $9.2 \%$ of calcium sulphate 2-hydrate, both percentages in mass. These samples with gypsum were designated as "sulphate" in the description of the results. Moreover, reference specimens without gypsum were also prepared, which were named as "reference" in the presentation and discussion of results. The water to cement ratio was 0.5 for all the cement pastes. For the setting of the samples, it was followed the procedure described in the Spanish and European standard UNE-EN 196-3.

Prismatic specimens were prepared with dimensions $25 \mathrm{~mm} \times 25 \mathrm{~mm} \times 285 \mathrm{~mm}$. During their first $24 \mathrm{~h}$, all specimens were kept in $95 \% \mathrm{RH}$ chamber and $20^{\circ} \mathrm{C}$. Once finished that period, they were de-moulded and they kept in the same optimum laboratory condition until the testing age.

\subsection{Experimental Tecniques}

The pore structure of the cement pastes was analyzed with mercury intrusion porosimetry. The porosimeter used was a Poremaster-60 GT manufactured by Quantachrome Instruments (Boynton Beach, FL, USA). The specimens were dried in an oven at $50{ }^{\circ} \mathrm{C}$ for $48 \mathrm{~h}$, before the test. The parameters studied in this work were total porosity, pore size distribution and mercury retained at the end of the test. The testing ages were at 1, 28 and 100 hardening days. Two measurements were made on each type of paste and the pieces tested were taken from specimens with dimensions $25 \mathrm{~mm}$ $\times 25 \mathrm{~mm} \times 285 \mathrm{~mm}$.

The possible expansion produced by the internal sulphate attack was followed according to the prescriptions of ASTM Standard C452-02 [6] up to 100 hardening ages. Three samples with dimensions $25 \mathrm{~mm} \times 25 \mathrm{~mm} \times 285 \mathrm{~mm}$ were used for this test.

Regarding the non-linear ultrasonic (NLU) technique, two transducers were used to simultaneously supply two pure tones $\left(f_{0}=20 \mathrm{kHz}\right.$ and $\left.\mathrm{f}_{1}=200 \mathrm{kHz}\right)$. The high-frequency probe signal was emitted with a signal generator (SONY AFG310) at an amplitude of 5 V. A 16-bit ADC resolution I/O device NI-USB 6361 was used for the generation of the low-frequency pump and the acquisition of the frequency modulated signal with a sampling frequency of $2 \mathrm{MHz}$. The pump wave signal was fed through an amplifier FS WMA-100 and then transmitted through a Langevin transducer. The input voltage was set to $140 \mathrm{~V}$ (after amplification). Two broadband ultrasonic transducers IDK09 were used for emitting and receiving the high-frequency signal. White soft paraffin (Acofarma) was used as a coupling agent. The signal registered was transformed to the frequency domain through the Fast Fourier Transform algorithm. Then, the amplitudes of the probe, the expected first harmonics and the intermodulation frequencies were used to evaluate the nonlinear parameter DIFA. In this work, the results of this parameter DIFA were presented [5]. Three samples for each one of paste types with dimensions $25 \mathrm{~mm} \times 25 \mathrm{~mm} \times 285 \mathrm{~mm}$ were tested up to 100 hardening age.

Finally, the linear ultrasonic pulse velocity was also determined in the same samples used for NLU technique. The equipment used was a Pundit Lab manufactured by Proceq (Schwerzenbach, 
Switzerland) and the measurement was made using direct transmission according to the Spanish and European standard UNE-EN 12504-4.

\section{Results and Discussion}

Regarding the results obtained through mercury intrusion porosimetry technique, the total porosities are depicted in Figure 1a. This parameter was higher for reference specimens compared to sulphate ones at one day of age. This could be due to the effect produced by the higher content of gypsum in the samples subject to sulphate attack, which would accelerate the hardening process at initial stages. At later ages, it has been observed a decrease of the total porosity, reaching lower values at 28 and 90 days for reference samples in comparison with sulphate ones.

The pore size distributions for the analyzed pastes can be observed in Figure 1b. At one hardening day, the microstructure was more refined for reference specimens, although the relative volume of pores with diameters smaller than $10 \mathrm{~nm}$ was higher for sulphate samples, which could be explained in relation to abovementioned influence of gypsum in the hardening of the samples in the very short-term. From 1 to 28 days, the reference pastes showed an important pore refinement, highlighting the rise of percentage of pores with sizes lower than $100 \mathrm{~nm}$ (pore ranges $<10 \mathrm{~nm}$ and 10-100 nm), and since then until 100 hardening ages, the pore structure of these pastes became slightly less refined. This could be due to the microstructure development due to the hydration of clinker $[7,8]$, which would progressively close the finer pores, reducing the porosity and the relative volume of pores of the smaller diameter ranges.

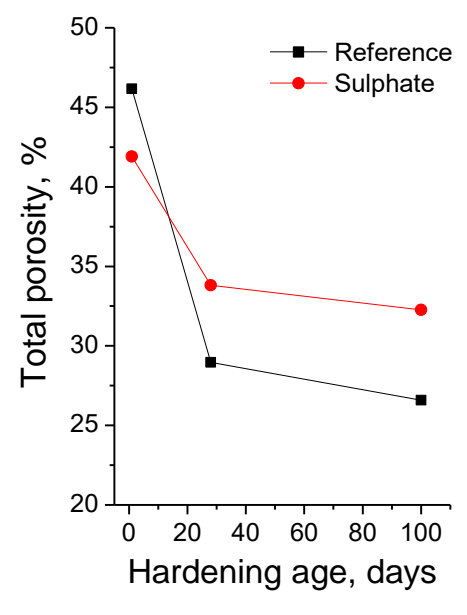

(a)

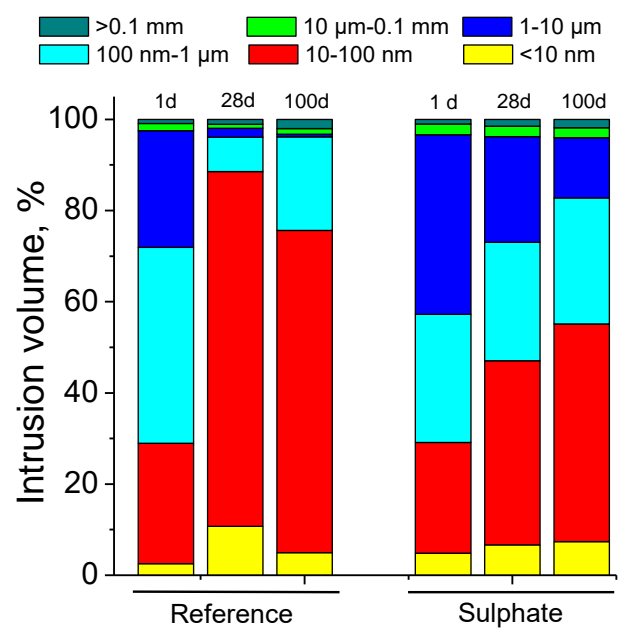

(b)

Figure 1. (a) Total porosity results for the studied cement pastes; (b) Pore size distributions for the analyzed samples.

In relation to the evolution of the pore size distribution of cement pastes exposed to internal sulphate attack, it gradually became more refined with time. However, at 28 and 100 hardening days, their pore network showed less refinement compared to references pastes. On one hand, the progressive closing of the microstructure of sulphate samples could be related to the development of clinker hydration and the consequent formation of solid phases [8], as has been previously explained for reference pastes. In addition to this, the initial stages of the sulphate attack entail the formation of products which also fill the existing pores [3], which would contribute to refine the pore network, until the pore is completely silted up, since when the attack would start damaging the microstructure. Nevertheless, the fact that microstructure was less refined at 28 and 90 days compared to reference ones, could be indicative that, simultaneously to silting of part of the pores due to clinker hydration and formation of initial products of sulphate attack, it would have pores already filled in which this attack would be starting to produce microcracking and breaking of microstructure. Despite that, the deleterious effects of internal sulphate attack were not generalized yet, and during the studied time 
period, it has been globally reported a pore refinement. Therefore, it would be expected that at later hardening ages, in further stages of the attack, the loss of pore refinement was more notably, at least for being detected with mercury intrusion porosimetry test [3].

The results of percentage of mercury retained in the specimen at the end of the test are represented in Figure 2a. This parameter is related to the tortuosity of the pore network. At one day, this parameter was higher for pastes subject to sulphate attack than for reference ones. This would show the abovementioned effect of gypsum in the first stages of hardening process, already explained. After 28 and 100 days, the $\mathrm{Hg}$ retained was greater for reference pastes, and the scarce decrease of this parameter noted for them between the abovementioned ages would be in keeping with the slight loss of refinement observed in their pore size distributions. In relation to sulphate specimens, their lower $\mathrm{Hg}$ retained would show a lower tortuosity of the pore structure, which would coincide with their less pore refinement compared to reference pastes. The reduction of the $\mathrm{Hg}$ retained from 28 to 100 days for pastes exposed to internal sulphate attack would indicate a reduction of the tortuosity of the pore microstructure. This could be produced by the silting of pores due to clinker hydration and the formation of initial products of sulphate, or it could also be due to the cracking produced by sulphate attack in already filled pores. A combination of both processes could be also suitable. Finally, the results of $\mathrm{Hg}$ retained were overall in agreement with other obtained with mercury intrusion porosimetry.

The length change due to expansion obtained for the studied pastes are represented in Figure $2 b$. As can be observed in that figure, an expansion has been observed for pastes subject to internal sulphate attack. This would confirm the hypothesis explained in the discussion of mercury intrusion porosimetry results about the presence of pores already silted in which a possible formation of microcracks due to expansion could be produced, despite of being other pores with still enough space for containing the expansive products of sulphate attack, where would not be happened cracking phenomenon yet.

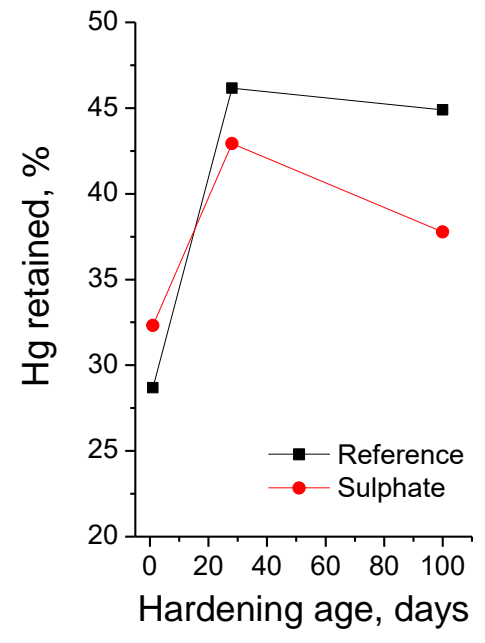

(a)

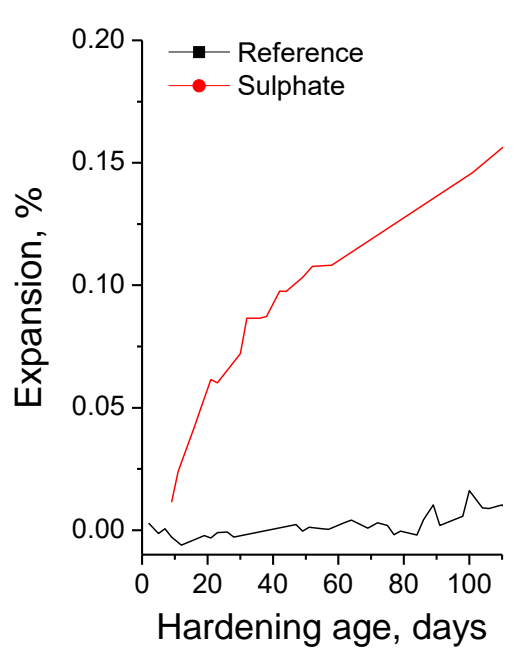

(b)

Figure 2. (a) Results of percentage of mercury retained at the end of porosimetry test; (b) Evolution of the expansion length change for the studied kinds of cement pastes.

With respect to NLU technique, the evolution of the parameter DIFA can be observed in Figure 3a. For reference samples, this parameter decreased in the short term and increased later, showing small changes during the studied time period in any case. On the other hand, the parameter DIFA continuously decreased with age for samples exposed to sulphate attack. This would mean that the system gradually turned less linear, which could indicate the beginning of deleterious effects produced by internal sulphate attack, with the formation of microcracks due to formation of expansive products. It is important to highlight that these trends described for parameter DIFA in 
both reference and sulphate pastes would be overall in keeping with the results of the length change due to expansion (see Figure 2b), which showed scarce changes for reference pastes and a progressive expansion for sulphate ones. Therefore, in view of these preliminary results, it seems that NLU technique could be useful for providing information about the deleterious processes due to internal sulphate attack.

The variation with time of linear ultrasonic pulse velocity for the studied samples is represented in Figure 3b. As can be observed, reference pastes showed the highest values of this parameter and it increased with time. This would indicate a lower global volume of voids in these samples and a higher proportion of pores of smaller sizes, which could coincide with the lower total porosity and the greater pore refinement of these reference pastes observed using mercury intrusion porosimetry. With respect to pastes subject to internal sulphate attack, the values of ultrasonic pulse velocity also showed a rising tendency with time, although they were lower in comparison with reference specimens. This result would suggest that sulphate pastes presented a higher volume of voids and a lower percentage of pores with smaller diameters. Again, this would be in agreement with the greater total porosity and the lower pore refinement noted for these sulphate samples using mercury porosimetry, compared to reference ones. Furthermore, the gradual growth of ultrasonic pulse velocity observed for sulphate pastes would show a reduction of the voids in these samples, which would also agree with the progressive microstructure refinement with age deduced from pore size distribution obtained with mercury intrusion porosimetry. Regarding the internal sulphate attack and the possible microcracking produced by the formation of expansive products, it had not been observed its effects in the linear ultrasonic pulse velocity results, at least during the time period studied.

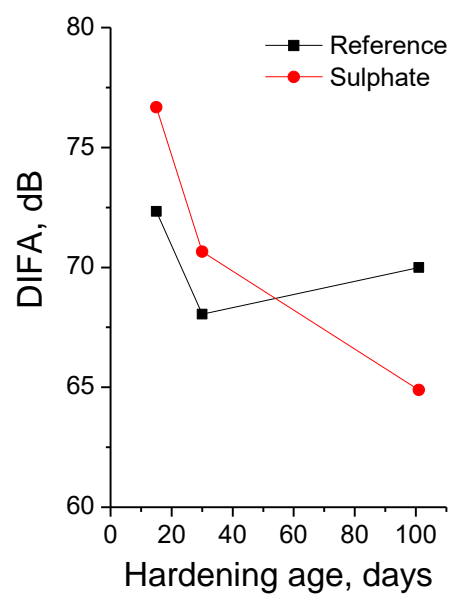

(a)

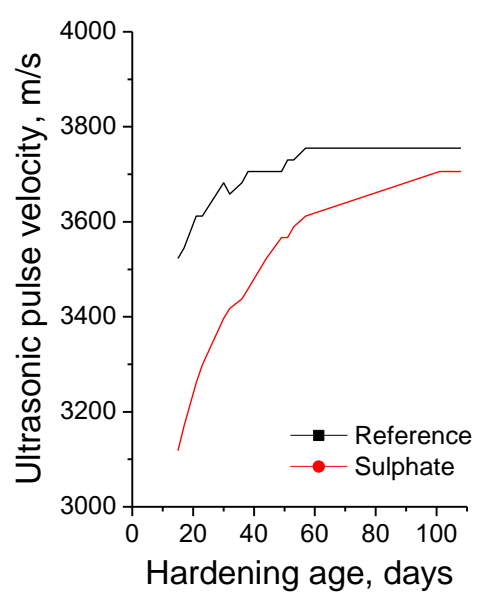

(b)

Figure 3. (a) Evolution of parameter DIFA also determined from NLU technique; (b) Linear ultrasonic pulse velocity results noted for the studied pastes.

\section{Conclusions}

The main conclusions to be drawn from the results previously discussed can be summarized as follows:

- The reference pastes showed an important pore refinement at 28 hardening days. This could be due to the microstructure development due to the hydration of clinker, which would progressively close the finer pores, reducing the porosity and the relative volume of pores of the smaller diameter ranges.

- The pore size distribution of cements pastes exposed to internal sulphate attack gradually became more refined with time, but this refinement was lower compared to reference pastes. This would suggest that simultaneously to the silting of part of the pores due to clinker hydration and formation of initial products of sulphate attack, it would have pores already filled 
in which this attack would be starting to produce microcracking of microstructure. Despite that, the deleterious effects of internal sulphate attack were not generalized yet, so it has been globally reported a pore refinement during the studied time period. Therefore, it would be expected that at later hardening ages, in further stages of the attack, the loss of pore refinement was more notably, at least for being detected with mercury intrusion porosimetry.

- A continuous expansion has been observed for pastes subject to internal sulphate attack. This would confirm the possible presence of pores already silted in which a possible formation of microcracks due to expansion could be produced.

- The tendencies observed for the NLU parameter DIFA were overall in keeping with the results of the length change due to expansion.

- Regarding linear ultrasonic pulse velocity, their results suggest a progressive reduction of voids with age in the studied samples, and it had not been observed effects of sulphate attack in this parameter.

- In view of these preliminary results, it seems that NLU technique could be useful for providing information about the deleterious processes due to internal sulphate attack in cement-based materials. Although more research would be needed for confirming this.

Author Contributions: Conceptualization, J.M.O., J.R. and M.Á.C.; methodology, J.M.O., J.R. and M.Á.C.; investigation, J.M.O., M.M., P.P. and A.J.T.-A.; data curation, J.M.O., M.M. and P.P.; writing-original draft preparation, J.M.O.; writing -review and editing, M.M. and A.J.T.-A.; supervision, J.R. and M.Á.C.; project administration, J.M.O., J.R. and M.Á.C.; funding acquisition, J.M.O., M.M. J.R. and M.Á.C. All authors have read and agreed to the published version of the manuscript.

Funding: This research was funded by the Conselleria de Educación, Investigación, Cultura y Deporte (at present re-named as Conselleria de Innovación, Universidades, Ciencia y Sociedad Digital) de la Generalitat Valenciana (Spain) (grant code GV/2019/070), by the Spanish Agencia Estatal de Investigación (grant code BIA2016-80982-R) and by the European Regional Development Fund (grant code BIA2016-80982-R). M. M. is indebted to Spanish Ministerio de Educación, Cultura y Deporte for a pre-doctoral fellowship (FPU16/04078).

Acknowledgments: Authors wish to thank Cementos Portland Valderrivas S.A. for providing the ordinary Portland cement used in this study.

Conflicts of Interest: The authors declare no conflict of interest.

\section{References}

1. Chen, J.; Jiang, M.; Zhu, J. Damage evolution in cement mortar due to erosion of sulphate. Corros. Sci. 2008, 50, 2478-2483, doi:10.1016/j.corsci.2008.05.021.

2. Santhanam, M.; Cohen, M.D.; Olek, J. Mechanism of sulfate attack: A fresh look. Part 1: Summary of experimental results. Cem. Concr. Res. 2002, 32, 915-921, doi:10.1016/S0008-8846(02)00724-X.

3. Ortega, J.M.; Esteban, M.D.; Rodríguez, R.R.; Pastor, J.L.; Ibanco, F.J.; Sánchez, I.; Climent, M. Long-term behaviour of fly ash and slag cement grouts for micropiles exposed to a sulphate aggressive medium. Materials (Basel) 2017, 10, doi:10.3390/ma10060598.

4. Climent, M.Á.; Miró, M.; Carbajo, J.; Poveda, P.; de Vera, G.; Ramis, J. Use of non-linear ultrasonic techniques to detect cracks due to steel corrosion in reinforced concrete structures. Materials (Basel) 2019, 12, doi:10.3390/MA12050813.

5. Climent-Llorca, M.Á.; Miró-Oca, M.; Poveda-Martínez, P.; Ramis-Soriano, J. Use of Higher-Harmonic and Intermodulation Generation of Ultrasonic Waves to Detecting Cracks due to Steel Corrosion in Reinforced Cement Mortar. Int. J. Concr. Struct. Mater. 2020, 14, doi:10.1186/s40069-020-00432-x.

6. ASTM. ASTM C 452-02 Standard Test Method for Potential Expansion of Portland-Cement Mortars Exposed to Sulfahte; American Society for Testing and Materials: West Conshohocken, PA, USA, 2002; Volume 2.

7. Escalante-García, J.I.; Sharp, J.H. Effect of temperature on the hydration of the main clinker phasesin Portland cements: Part II, blended cements. 1998, 28, 1259-1274.

8. Ortega, J.M.; Sánchez, I.; Climent, M.A. Impedance spectroscopy study of the effect of environmental conditions in the microstructure development of OPC and slag cement mortars. Arch. Civ. Mech. Eng. 2015, 15, 569-583, doi:10.1016/j.acme.2014.06.002. 
Publisher's Note: MDPI stays neutral with regard to jurisdictional claims in published maps and institutional affiliations.

(C) 2020 by the authors. Submitted for possible open access publication under the terms and conditions of the Creative Commons Attribution (CC BY) license (http://creativecommons.org/licenses/by/4.0/). 